\title{
The Preferred Management of a Single-Digit Distal Phalanx Amputation
}
${ }^{1}$ Division of Reconstructive Microsurgery, Department of Plastic and Reconstructive Surgery, Chang Gung Memorial Hospital, Linkou Medical Center and Chang Gung Medical College and Chang Gung University, Taoyuan, Taiwan
2 Department of Plastic Surgery, Maastricht University Medical Center, Maastricht, The Netherlands
3 Department of Plastic, Reconstructive and Aesthetic Surgery, Hand surgery, Alfried Krupp Hospital, Essen, Germany
${ }^{4}$ Department of Otolaryngology, National Taiwan University Hospital, Taipei, Taiwan

Soo-Ha Kwon, MD ${ }^{1}$ William Wei-Kai Lao, MD ${ }^{1}$ Angela Ting-Wei Hsu, MD ${ }^{1}$ Che-Hsiung Lee, MD ${ }^{1}$ Chung-Chen Hsu, MD ${ }^{1}$ Jung-Ju Huang, MD, FACS ${ }^{1}$ Shan Shan Qiu, MD, PhD ${ }^{2}$ Daniel Tilkorn, MD, PhD ${ }^{3}$ Evelyn Ting-Hsuan Tang, MD ${ }^{1,4}$ Johnny Chuieng-Yi Lu, MD ${ }^{1}$ Tommy Nai-Jen Chang, MD ${ }^{1}$

J Reconstr Microsurg 2020;36:301-310.

\begin{abstract}
Keywords

- distal phalanx reconstruction

- replantation

- questionnaire

Background Replantation of a single digit at the distal phalanx level is not routinely performed since it is technically challenging with questionable cost-effectiveness. The purpose of this study was to analyze international microsurgeons' clinical decisions when faced with this common scenario.

Methods A survey of a right-middle finger distal phalanx transverse complete amputation case was conducted via online and paper questionnaires. Microsurgeons around the world were invited to provide their treatment recommendations. In total, 383 microsurgeons replied, and their responses were stratified and analyzed by geographical areas, specialties, microsurgery fellowship training, and clinical experiences.

Results Among 383 microsurgeons, $170(44.3 \%)$ chose replantation as their preferred management option, 137 (35.8\%) chose revision amputation, 62 (16.2\%) chose local flap coverage, 8 (2.1\%) chose composite graft, and $6(1.6 \%)$ favored other choices as their reconstruction method for the case study. Microsurgeons from the Asia-Pacific, Middle East/South Asia, and Central/South America regions tend to perform replantation $(70.7,68.8$, and $67.4 \%$, respectively) whereas surgeons from North America and Europe showed a lower preference toward replantation (20.5 and $26.8 \%$, respectively $p<0.001)$. Having completed a microsurgery fellowship increased the attempt rate of replantation by $15.3 \%(p=0.004)$. Clinical experience and the surgeons' specialties did not show statistical significance in clinical decision making.

Conclusion From the present study, the geographic preferences and microsurgery fellowship experience influence the method of reconstruction for distal phalanx amputation. Multiple factors are taken into consideration in selecting the most suitable reconstructive method for each case scenario. In addition to the technical challenges of the proposed surgery, the cost of the procedure and the type of facility needed are important variables in the decision making process.
\end{abstract}

Address for correspondence Tommy Nai-Jen Chang, MD, Division of Reconstructive Microsurgery, Department of Plastic and Reconstructive Surgery, Chang Gung Memorial Hospital, Linkou Medical Center and Chang Gung Medical College and Chang Gung University, No. 5, Fu-Hsing Street Kwei-Shan, Taoyuan, Taiwan (e-mail: tommynjchang@yahoo.com.tw). received

July 20, 2019

accepted after revision

December 2, 2019

published online

February 5, 2020 
From current literature, the accepted indications for digit replantation are thumb amputation, multiple digit amputation, pediatric amputation, and amputation at the level of distal phalanx. ${ }^{1}$ Distal phalanx amputation is a common clinical scenario. Replantation is recommended since vital structures including the fingertip glabrous skin, bone, and nail can be preserved, achieving functional and cosmetic outcomes without donor site morbidity. The recent success rate of Tamai Zone I replantation is up to 70 to $90 \% .2,3$ However, performing replantation at this level is technically demanding and requires long-operation time and hospitalization. Potential complications arising from surgery and the time required for a patient to return to work are additional concerns; and cost-effectiveness also plays a significant role in the decision-making process. ${ }^{4}$ Often, microsurgeons are reluctant to perform replantation because this long procedure also disrupts their surgical schedule and there is no financial incentive. Therefore, we hypothesized that the overall attempt rate of performing distal phalanx replantation is low and that such cases are usually managed with alternative methods. $^{5-8}$

In distal phalanx amputation, when the amputated part is unavailable, various choices of reconstruction exist. Secondary healing, direct closure, skin graft, local flap, distant flap, and free flap coverage can all be used. These surgical approaches are usually easier than replantation, but the results are presumably inferior since these alternative methods cannot substitute for the complex structure of the distal phalanx. In addition, all these reconstructive methods have donor site morbidities. Thus, all factors considered, the decision for the most appropriate management should be based on the general medical condition, patient's expectation, surgeon's skill, facilities at the institute, and the insurance system altogether. ${ }^{5-7,9}$
To understand the decision-making process of microsurgeons around the world, when faced with this particular scenario, a case study was conducted and surgeons around the world were invited to present their clinical strategy through an online questionnaire.

\section{Methods}

\section{Questionnaire Design}

The questionnaire was designed with Google Forms. ${ }^{10}$ Part one of the questionnaire was basic information of the survey participant, followed with 10 case scenarios and one-to-two questions related to treatment options. Participants completed questions pertaining to nationality, seniority (years as a microsurgery staff, more than 5 years of staff experience defines as a senior microsurgeon whereas less than 5 years defines as a junior microsurgeon), experience of microsurgery fellowship training, and specialty (hand surgeon/plastic surgeon/orthopaedics). At the beginning of the questionnaire, a case with a brief history and key photographs was shown. The replantation case had: a 44-year-old male who sustained a transverse amputation injury of the right middle finger at the level of the distal phalanx (Tamai zone I). The participants were asked to state their preferred choices for reconstruction in this case (-Fig. $\mathbf{1}$ ).

To the best of our knowledge, this is the first study that collects the opinions of global microsurgeons toward a common clinical scenario. Different modalities (paper and online surveys) were used to collect the responses; the only drawback is that the response rate could not be precisely calculated. Around 100 paper questionnaires were administrated at the 5th World Symposium for Lymphedema Surgery (Chang-Gung Memorial Hospital, Taoyuan, Taiwan, 2016),

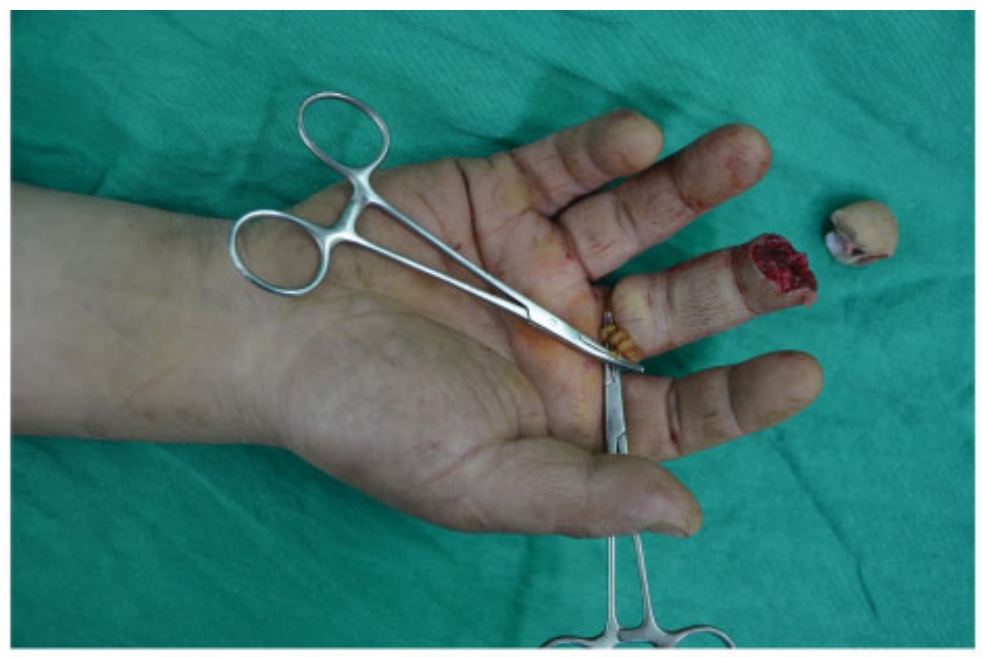

\begin{tabular}{|l|l|}
\hline - 44-year-old male & Q: What is your choice \\
- Right middle finger amputation at & of reconstruction? \\
distal phalanx level & Ans: \\
- No distal interphalangeal joint injury & \\
- Good quality of amputated part & \\
\hline
\end{tabular}

Fig. 1 The illustrated case and the question in this questionnaire. 
the response rate was $30 \%$. The electronic version of the questionnaire was first distributed via personal e-mails, ResearchGate, ${ }^{11}$ and LinkedIn ${ }^{12}$ accounts; up to 3,000 invitations sent and the response rate was around 3 to $5 \%$. To receive the maximal responses, we then adapted the Facebook platform. ${ }^{13}$ The senior author Dr. Tommy Nai-Jen Chang had established the platform "International Microsurgery Club (IMC)" with microsurgeons around the world as members. ${ }^{14-18}$ The social medial platform is an effective method of deliver thoughts and information. ${ }^{19,20}$ We invited all group members to respond to the questionnaire via Facebook Messenger and posted this information on the group page three times. The Facebook Messenger is more interactive than e-mail, so the response rate was higher (200/400, 50\%). However, it was impossible to calculate the survey response rate via the Facebook platform because there was no way to know how many members actually read the open post. Only attending level microsurgeons were invited to participate in the study, residents and fellows were excluded. Data collection was done from May 2016 to November 2016. To be eligible for inclusion, microsurgeons need to meet at least one of the following criteria: microsurgery fellowship trained, have active microsurgery patients in clinical practice, belong to departments, and specialties that routinely perform microsurgery. In total, 383 microsurgeons participated in this study. Their responses were analyzed thoroughly, and stratified by geographical areas, whether fellowship trained or not, department where they worked (plastic, orthopaedic, or hand surgery) and their seniority (years as an attending physician).

\section{Statistics}

Statistical analysis was conducted using SPSS software version 22.0 (SPSS 22.0 software for Mac; SPSS Inc., Chicago, IL). Differences in the proportions of dichotomous variables were tested with Fisher's exact test, whereas differences in the location parameters of continuous variables were tested with the independent-sample Mann-Whitney $U$-test. For univariant and multivariant analysis, binary logistic regression was applied for predict model. All $p$-values were two-sided, and the significance level was set at $p<0.05$.

\section{Results}

In total, 383 microsurgeons from all over the world were enrolled for the analysis (-Table 1). Among 383 microsurgeons, 170 (44.4\%) chose replantation as their preferred management option, and 137 (35.8\%) preferred revision amputation, 62 (16.2\%) chose various local flap coverage, 8 (2.1\%) favored composite graft, and 6 (1.6\%) favored other choices as their method of reconstruction for the presented case (all classified into "others," $n=213$ in total). (-Fig. 2).

Microsurgeons from the Asia Pacific, Middle East/South Asia, and Central/South America were more likely to perform replantation (70.7, 68.8, and 67.4\%); whereas only 26.8 and $20.5 \%$ of microsurgeons from Europe and North America preferred replantation, respectively ( $p<0.001$; - Fig. 3, - Table 2$)$.

Using the North America rate as the reference, the differences in replantation rate in Middle East/South Asia, Asia Pacific, Central/South America, and Africa were statically

Table 1 The international microsurgeons participated in the study

\begin{tabular}{|c|c|c|c|c|c|c|}
\hline $\begin{array}{l}\text { South Asia and } \\
\text { Middle East }\end{array}$ & Asia Pacific & Oceania & Europe & North America & $\begin{array}{l}\text { Central and } \\
\text { South America }\end{array}$ & Africa \\
\hline$n=32$ & $n=75$ & $n=3$ & $n=112$ & $n=78$ & $n=32$ & $n=40$ \\
\hline India: 17 & Taiwan: 30 & Australia: 3 & Germany: 33 & United Sates: 70 & Mexico: 17 & Egypt: 22 \\
\hline Turkey: 3 & Japan: 9 & & Netherland: 14 & Canada: 8 & Colombia: 6 & South Africa: 6 \\
\hline Yemen: 2 & Indonesia: 8 & & Austria: 8 & & Argentina: 4 & Sudan: 5 \\
\hline Pakistan: 2 & China: 7 & & United Kindem: 7 & & Brazil: 4 & Nigeria: 4 \\
\hline Saudi: 2 & South Korea: 5 & & Spain: 6 & & Venezuela: 4 & Ghana: 1 \\
\hline Bangladesh: 1 & Thailand: 5 & & Sweden: 4 & & Peru: 3 & Algeria: 1 \\
\hline Iraq: 1 & Hong Kong: 4 & & Finland: 3 & & Chile: 2 & Kenya: 1 \\
\hline Israeli: 1 & Philippines: 2 & & France: 3 & & Nicaragua: 1 & \\
\hline Jordan: 1 & Singapore: 2 & & Russia: 3 & & El Salvador: 1 & \\
\hline Kuwait: 1 & Malaysia: 1 & & Switzerland: 3 & & & \\
\hline \multirow[t]{7}{*}{ Syria: 1} & Myanmar: 1 & & Croatia: 2 & & & \\
\hline & Vietnam: 1 & & Portugal: 2 & & & \\
\hline & & & Poland: 2 & & & \\
\hline & & & Greece: 2 & & & \\
\hline & & & Denmark:1 & & & \\
\hline & & & Norway: 1 & & & \\
\hline & & & Belgium: 1 & & & \\
\hline
\end{tabular}

Note: Nationality was classified into seven groups geographically. 


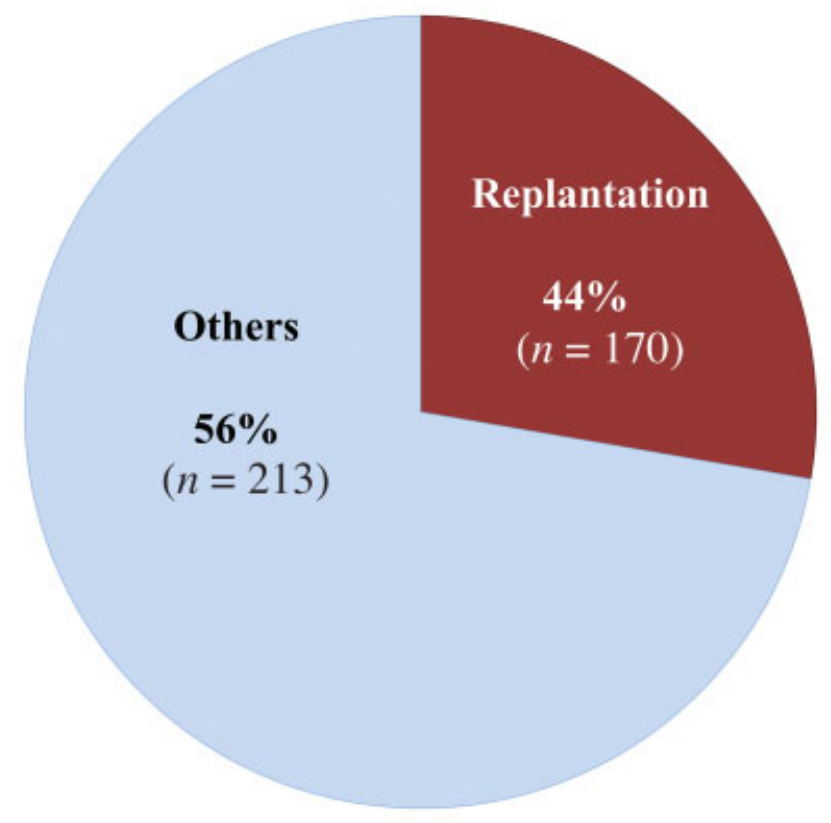

Fig. 2 The overall rate of participants who chose replantation as their reconstruction options. In total, $44 \%$ microsurgeons chose replantation whereas the other $56 \%$ chose other methods for reconstruction. significance in the choice of replantation. $(p<0.001$, multivariate study; - Fig. 3, - Tables 3 and 4). Having done a microsurgery fellowship, the rate of attempting replantation increased by $15.3 \%$. ( 49.6 vs. $34.3 \%, p=0.04$ in the univariate analysis, $p=0.022$ in the multivariate analysis; - Fig. 4, -Table 4) There were no statistically significant differences associated with seniority, which was divided into senior or junior surgeon status with the cut off of 5 clinical staff years, also no statistical significance whether surgeons were from the plastic surgery, orthopaedic, or hand surgery departments (-Figs. 5 and 6, - Table 4).

\section{Discussion}

The goals of distal phalanx reconstruction include length preservation, pain free contact surface restoration, obtaining durable and sensate skin coverage, and nail plate preservation with acceptable cosmesis. ${ }^{21}$ The success rate of the digit replantation mainly relies on the clinical condition, trauma mechanism, surgical skill, and microsurgeon's preferences. The success of replantation is multifactorial. Operative strategies, such as the two-stage operation for venous anastomosis ${ }^{22}$ and using volar vein for anastomosis ${ }^{23}$ can increase replantation success. Other factors, such as replantation done in daylight hours, ${ }^{24}$ the use of medical leeches and the removal of nail plate from the replanted

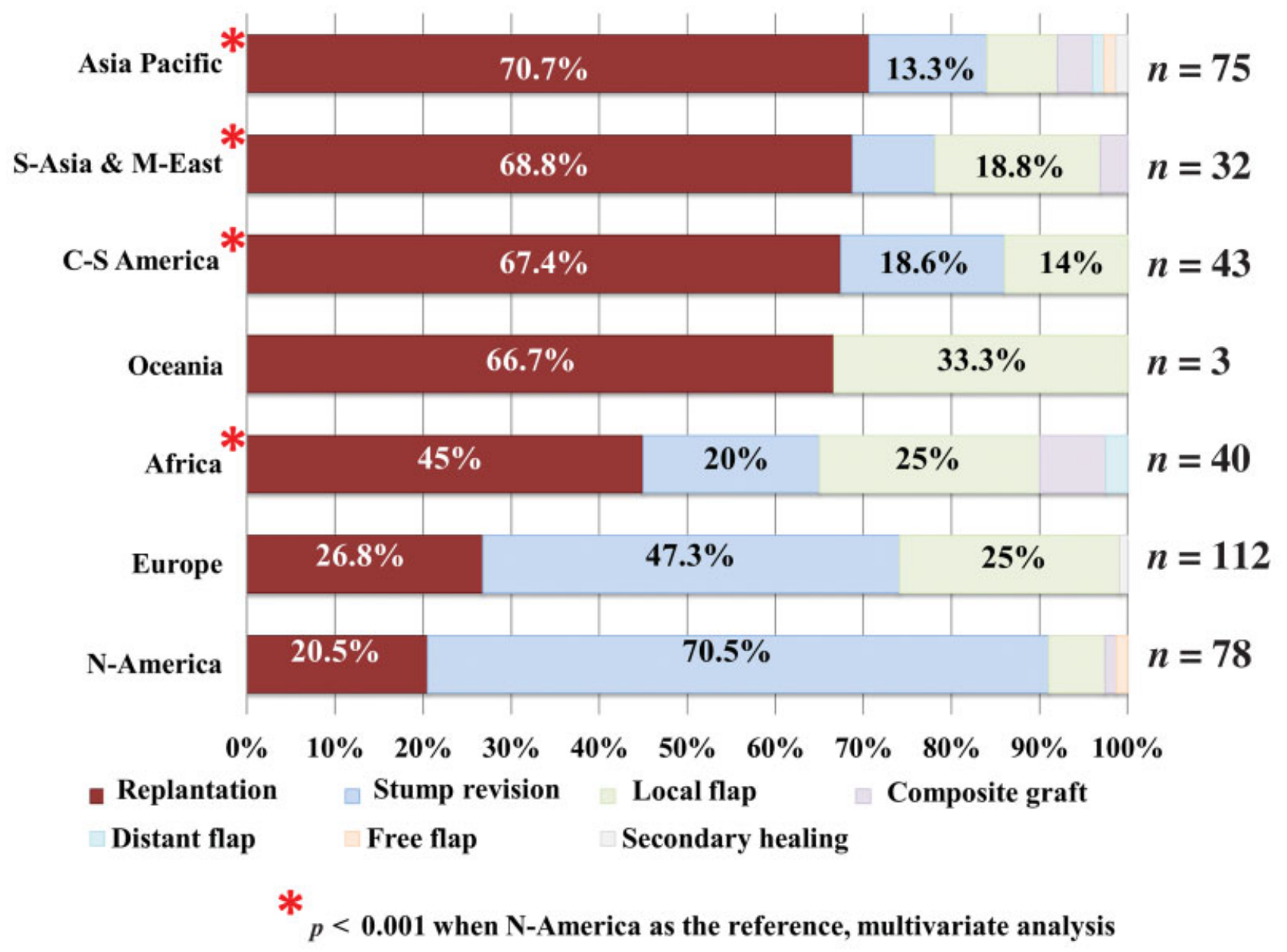

Fig. 3 Geographically, Asia Pacific, South Asia/Middle East, and Central/South America were more likely to perform replantation, whereas Europe and North America were less likely. 
Table 2 General descriptive data between replantation compared with nonreplantation with Chi-square comparison

\begin{tabular}{|c|c|c|c|}
\hline & Replantation & $\begin{array}{l}\text { No Replantation } \\
\text { (all the other options) }\end{array}$ & \\
\hline & Number (\%) & Number (\%) & $p$-Value \\
\hline $\begin{array}{l}\text { Q1. Have you done any microsurgery } \\
\text { fellowship training in your career? }\end{array}$ & 168 & 213 & $0.004^{\mathrm{a}}$ \\
\hline Yes & $47(28)$ & $90(42.3)$ & \\
\hline No & $121(72)$ & $123(57)$ & \\
\hline Q2. Geographic area & 170 & 213 & $<0.001^{\mathrm{a}}$ \\
\hline South Asia and Middle East & $22(12.9)$ & $10(4.7)$ & \\
\hline Asia Pacific & $53(31.2)$ & $22(10.3)$ & \\
\hline Central-South America & $29(17.1)$ & $14(6.6)$ & \\
\hline Europe & $30(17.6)$ & $82(38.5)$ & \\
\hline North America & $16(9.4)$ & $62(29.1)$ & \\
\hline Africa & $18(10.6)$ & $22(10.3)$ & \\
\hline Oceania & $2(1.2)$ & $1(0.5)$ & \\
\hline Q3. Seniority & 168 & 210 & 0.490 \\
\hline Junior ( $<5$ staff year) & $59(35.1)$ & $81(38.6)$ & \\
\hline Senior ( $>5$ staff year) & $109(64.9)$ & $129(61.4)$ & \\
\hline Q4. Specialty & 166 & 207 & 0.866 \\
\hline Plastic surgery & $132(79.5)$ & $168(81.2)$ & \\
\hline Orthopaedics & $16(9.6)$ & $20(9.7)$ & \\
\hline Hand surgery & $18(10.8)$ & $19(9.2)$ & \\
\hline
\end{tabular}

${ }^{a} p<0.05$.

Table 3 Univariate Analysis for replantation compared with nonreplantation: geographic area comparison

\begin{tabular}{|l|l|l|l|l|l|l|l|}
\hline & $\begin{array}{l}\text { South Asia and } \\
\text { Middle East }\end{array}$ & Asia Pacific & $\begin{array}{l}\text { Central and } \\
\text { South America }\end{array}$ & Europe & North America & Africa & Oceania \\
\hline $\begin{array}{l}\text { South Asia and } \\
\text { middle east }\end{array}$ & Reference & 0.913 & 1.062 & $6.013^{\mathrm{a}}$ & $8.525^{\mathrm{a}}$ & $2.689^{\mathrm{a}}$ & 1.100 \\
\hline Asia Pacific & 1.095 & Reference & 1.163 & $6.585^{\mathrm{a}}$ & $9.335^{\mathrm{a}}$ & $2.944^{\mathrm{a}}$ & 1.205 \\
\hline $\begin{array}{l}\text { Central and } \\
\text { south America }\end{array}$ & 0.942 & 0.860 & Reference & $5.662^{\mathrm{a}}$ & $8.027^{\mathrm{a}}$ & $2.532^{\mathrm{a}}$ & 1.036 \\
\hline Europe & $0.166^{\mathrm{a}}$ & $0.152^{\mathrm{a}}$ & $0.177^{\mathrm{a}}$ & Reference & 1.418 & $0.447^{\mathrm{a}}$ & 0.183 \\
\hline North America & $0.117^{\mathrm{a}}$ & $0.107^{\mathrm{a}}$ & $0.125^{\mathrm{a}}$ & 0.705 & Reference & $0.315^{\mathrm{a}}$ & 0.129 \\
\hline Africa & $0.372^{\mathrm{a}}$ & $0.340^{\mathrm{a}}$ & $0.395^{\mathrm{a}}$ & $2.236^{\mathrm{a}}$ & $3.170^{\mathrm{a}}$ & Reference & 0.409 \\
\hline Oceania & 0.909 & 0.830 & 0.966 & 5.467 & 7.750 & 2.444 & Reference \\
\hline
\end{tabular}

Note: The number means odds ratio (OR) compared with vertical column. ${ }^{\mathrm{a}} \mathrm{p}<0.05$.

finger to promote bleeding, ${ }^{2}$ artery-only anastomosis in fingertip replantation, ${ }^{25}$ and combined with the subdermal pocket procedure, ${ }^{26}$ all may increase success rate for better outcome. In our study, we presented the case of a laborer who suffered from a complete amputation of the right-middle finger just distal to the distal phalangeal joint level (Tamai zone I). Although an appropriate indication for replantation, only $44.4 \%$ of microsurgeons selected replantation as their preferred management option. Despite the stated benefits of replantation in the literature and recent advances in microsurgery, clinical attempt rate for replantation at the distal phalanx level remains low. ${ }^{27,28}$
Geographically we divided the microsurgeons into seven groups, including Asia Pacific, South Asia, and Middle East including Turkey, North America, Central to South America, Oceania, Africa, and Europe including Russia. The microsurgeons from Asia-Pacific, Middle East/South Asia, and Central/ South America were more likely to perform replantation (70.7, 68.8, and 67.4\%), whereas those from Europe and North America microsurgeons were less likely to attempt replantation at this level $(26.8$ and $20.5 \%, p<0.01)$. We hypothesized that geographical areas with a higher preference for replantation were also more interested in super-microsurgery. Literature search for 
Table 4 Univariate and multivariate analysis for replantation compared with nonreplantation: other associated factors analysis

\begin{tabular}{|c|c|c|c|c|c|c|c|}
\hline \multirow[b]{2}{*}{ Factors } & & \multicolumn{3}{|c|}{$\begin{array}{l}\text { Univariate Analysis for replantation } \\
\text { compared with nonreplantation }\end{array}$} & \multicolumn{3}{|c|}{$\begin{array}{l}\text { Multivariate Analysis for replantation } \\
\text { compared with nonreplantation }\end{array}$} \\
\hline & & Odds ratio & $\begin{array}{l}95 \% \\
\text { confidence } \\
\text { interval }\end{array}$ & $p$-Value & Odds ratio & $\begin{array}{l}95 \% \\
\text { confidence } \\
\text { interval }\end{array}$ & $p$-Value \\
\hline \multirow[t]{2}{*}{ Fellowship } & No & Reference & & & Reference & & \\
\hline & Yes & 1.884 & $1.222-2.904$ & $0.004^{a}$ & 1.832 & $1.089-3.081$ & $0.022^{a}$ \\
\hline \multirow[t]{2}{*}{ Seniority } & Junior & Reference & & & Reference & & \\
\hline & Senior & 1.16 & $0.761-1.768$ & 0.490 & 1.551 & $0.933-2.579$ & 0.091 \\
\hline \multicolumn{8}{|l|}{ Specialty } \\
\hline & Plastic surgeon & Reference & & & Reference & & \\
\hline & Orthopaedics & 1.018 & $0.508-2.042$ & 0.960 & 0.99 & $0.447-2.190$ & 0.980 \\
\hline & Hand surgeon & 1.206 & $0.609-2.389$ & 0.592 & 1.236 & $0.551-2.774$ & 0.608 \\
\hline \multirow[t]{7}{*}{ Nationality } & North America & Reference & & & Reference & & \\
\hline & $\begin{array}{l}\text { South Asia and } \\
\text { Middle East }\end{array}$ & 8.525 & $3.371-21.559$ & $<0.001^{\mathrm{a}}$ & 12.919 & $4.725-35.323$ & $<0.001^{a}$ \\
\hline & Asia Pacific & 9.335 & 4.449-19.586 & $<0.001^{\mathrm{a}}$ & 12.631 & $5.649-28.241$ & $<0.001^{\mathrm{a}}$ \\
\hline & $\begin{array}{l}\text { Central and } \\
\text { south America }\end{array}$ & 8.027 & $3.458-18.630$ & $<0.001^{a}$ & 9.102 & $3.767-21.994$ & $<0.001^{\mathrm{a}}$ \\
\hline & Europe & 1.418 & $0.711-2.828$ & 0.322 & 2.052 & $0.973-4.326$ & 0.059 \\
\hline & Africa & 3.170 & $1.381-7.276$ & $0.006^{a}$ & 5.513 & $2.167-14.024$ & $<0.001^{\mathrm{a}}$ \\
\hline & Oceania & 7.750 & $0.66-90.945$ & 0.103 & 7.377 & $0.615-88.487$ & 0.115 \\
\hline
\end{tabular}

${ }^{a} p<0.05$.

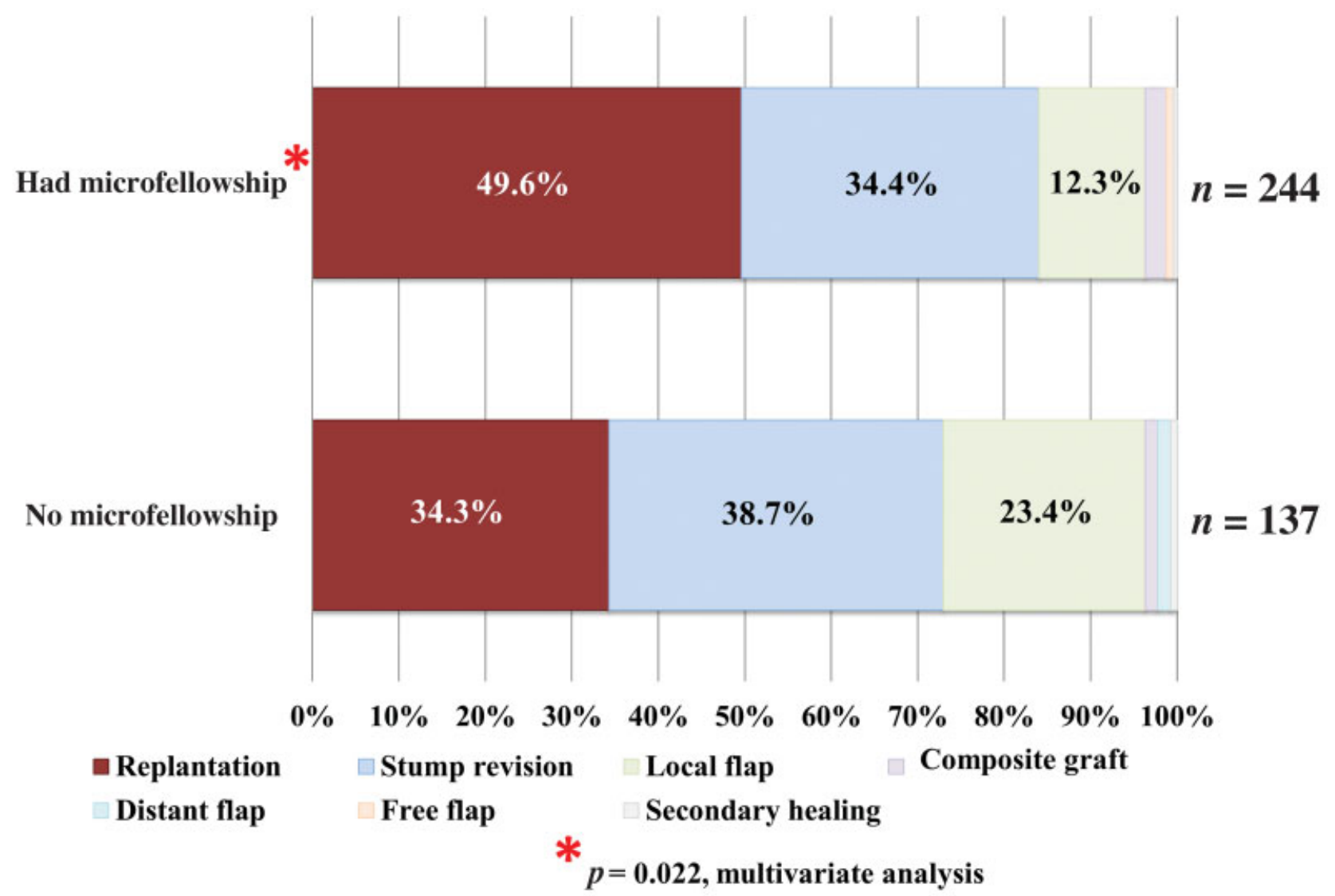

Fig. 4 The microsurgeons who had completed microsurgical fellowships showed higher interest in replantation reconstruction for the studied case. 


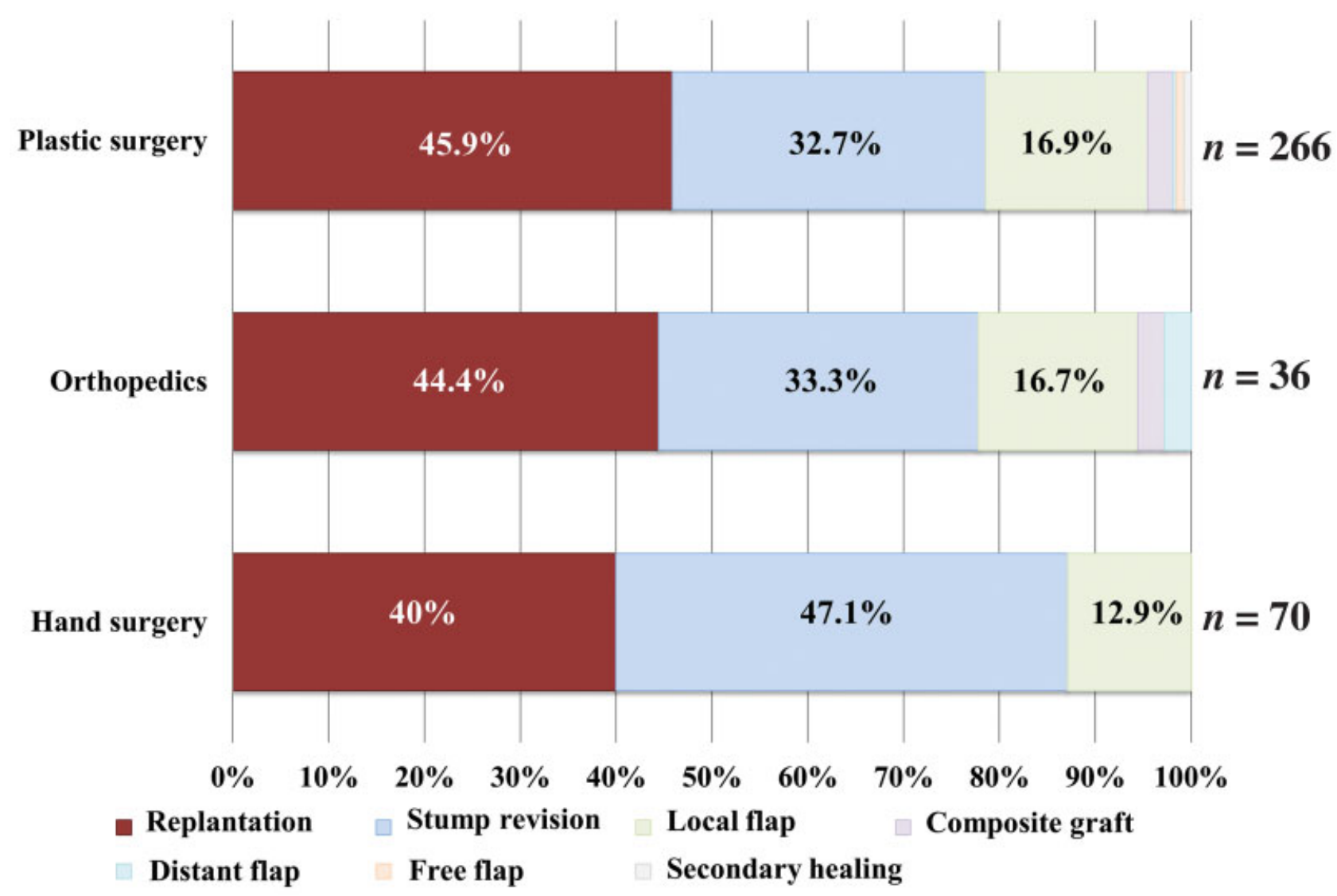

Fig. 5 The microsurgeons with different specialties did not have significant preference differences in choice of reconstructive option toward to the studied case.

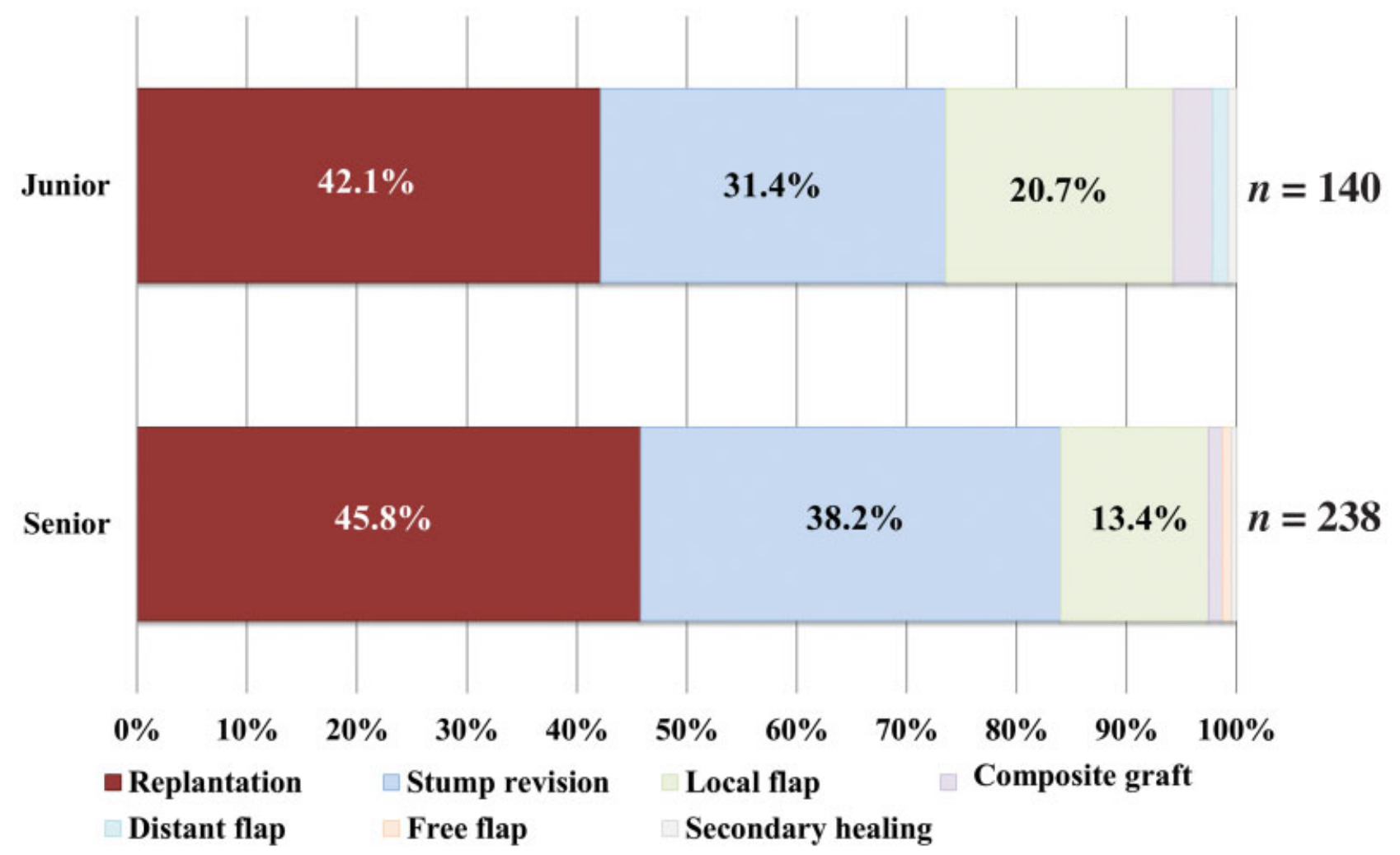

Fig. 6 The preferences between junior and senior microsurgeons were not significantly different. 
recent super-microsurgery publications further supported that. A search on PubMed using the keywords "fingertip replantation," "distal phalanx replantation," and "free pulp replantation." Identified 30 publications within the past 5 years (2012-2016). Of these, 22 (73.3\%) were from Asia-Pacific areas (Korea $=7$, China $=6$, Taiwan $=3$, Japan $=3$, and Singapore $=2)$ and the remainders were from Turkey $(n=4)$, Australia $(n=1)$, Germany $(n=1)$, the Czech Republic $(n=1)$, the United States $(n=1)$, and France $(n=1)$.

Even though many important developments of microsurgery started in Europe and North America, these regions are currently less interested in a procedure like distal phalanx replantation. ${ }^{29}$ The possible reasons might be as follows:

- Replantation at this level is technically difficult from the dissection and anastomosis of the small caliber vessels and the management of postoperative venous congestion. ${ }^{22,25,30-33}$ Some techniques and adjuvant treatments proposed to improve the replant success rate include: dissection of the reverse digital artery, polypropylene suture guided interposition vein graft, delayed venous anastomosis, fish-mouth incision, fingernail removal, medical leech application, heparinized saline gauze soaking, negative pressure wound therapy, and subdermal pocket. These advances in microsurgery lead to a success rate of up to 78 to $96 \%$; however, most microsurgeons still think distal phalanx replantation is a difficult task. ${ }^{26,34-37}$

- (2) The cost-effectiveness of replantation is still questionable. Although a successful replantation is optimal compared with a revision amputation or other methods of reconstruction, the drawbacks of prolong operative time and hospitalization, delayed complications, and delayed return to work still remain as problems. ${ }^{8,9}$

- (3) From the functional hand's point of view, the loss of part of the distal phalanx does not impose much of a functional deficit, the main complaint is cosmesis. ${ }^{5} \mathrm{How}-$ ever, in our study, we have identified some area, such as Asian Pacific area prone to replant the amputated digits if possible. There are two possible explanations as follows: (1) in oriental countries, people regard body integrity and physical appearance as more important than function; therefore, many patients in those areas strongly request replantation even after being informed that it is not essential for hand function; and (2) The microsurgeons in this area may more familiar with the supermicrosurgery, therefore this injury is less-technical challenging and the decision of replantation is more possible. ${ }^{38}$

- (4) The replantation surgery disrupts the regular operating room schedule. In many hospitals, only few microsurgeons, operative theaters, and microsurgery set up are available. Therefore, sometimes it is reasonable that they would rather choose an easier method to finish the reconstruction. Even in expert's hands, a distal phalanx replantation still requires 3 to 4 hours. A replantation surgery usually disrupts the scheduled cases and often presents late in the night. Both reasons decrease the attempt rate of replantation.
- (5) In most hospitals, the microsurgeons do not receive additional financial incentives even for complicated operation. Therefore, distal phalanx amputations have usually been managed with other alternative methods. ${ }^{5-7}$

The results of this study revealed that Middle East/South Asia and Central/South America showed higher interest in replantation. The reason for this may be that microsurgeons in these areas are interested in gaining microsurgical experience through replantation because these regions are thought to be the developing areas of microsurgery.

A microsurgical fellowship is an important factor in favoring replantation in our case. Among surgeons with a microsurgical fellowship, the replantation rate increased by $15.3 \%$ compared with those without a microsurgical fellowship. A microsurgery fellowship may represent more than just additional training; it is a process of professional and personal development that indicates the willingness to take on challenging cases and overcome the obstacles in plastic surgery. ${ }^{37}$

\section{Limitations}

Despite novel investigative methods and approaches with significant findings, this study has some limitations. First, our participants were microsurgeons but the case was more familiar to hand surgeon. In many places, hand surgeons were not microsurgeons because some of them were orthopaedic hand surgeons. It may make our study had bias with higher rate of replantation. Second, the exact geographical classification of microsurgeon is almost impossible since the culture may be hugely varied within the same continent, and sometimes similar cultures cross two continents. Therefore, we split Asia into Asia Pacific and South Asia/Middle East, also merged Central and South America, since they both belong to Latin America. However, few countries like Russia and Turkey which span both Europe and Asia continents are difficult to classify geographically. Third, the experiences of a given microsurgeon cannot be clearly quantified, including their training background, number of cases performed, and the surgical technique, and success rate. For example, a young microsurgeon specializing in head and neck reconstruction may have more experience than a senior microsurgeon. Forth, the responses to the questionnaire may differ from what is actually performed when faced with such a case. For example, a few microsurgeons commented that although they preferred replantation in this study case, they were not familiar with the setup of the replantation and preferred to revise the stump, owing to their greater experience with this technique. Fifth, although our sample size is 383, it could not represent the opinion of the entire global microsurgeons; in addition, the small sample size in each geographic group may not represent the general consensus of the whole region. Sixth, extrinsic factors not reflected by the questionnaire might also affect the decision to replant, such as surgeon's working place (private clinic, state hospital, university hospital, etc.), the resources in operative theater (microscope availability), manpower, and the postoperation care system. Lastly, because the questionnaire was spread online, some countries where platform like 
Facebook were not available will be excluded automatically, and the response rate cannot be calculated.

In our study, the respondents were selected from professional societies or invited by experts, so that nonprofessional opinions were excluded. The online questionnaire saved time and financial resources while making a global survey feasible.

\section{Conclusion}

Many factors are involved when microsurgeons make decisions toward a particular case. To the best of our knowledge, this study is the first one using popular social media to report the global microsurgeon's opinion on a common clinical scenario. The result identified geographical differences, which corresponds to the number of related studies published from respective countries in the recent literatures. In addition, the significance of a microsurgical fellowship on clinical decision making was highlighted.

\section{Conflict of Interest}

None declared.

\section{References}

1 Mulders MA, Neuhaus V, Becker SJ, Lee SG, Ring DC. Replantation and revascularization vs. amputation in injured digits. Hand (N Y) 2013;8(03):267-273

2 Aksoy A, Gungor M, Sir E. Fingertip replantation without and with palmar venous anastomosis: analysis of the survival rates and vein distribution. Ann Plast Surg 2017;78(01):62-66

3 Purisa H, Ozturk MB, Kabakas F, Mersa B, Ozcelik IB, Sezer I. Intramedullary venous drainage system for distal fingertip replantations. Ann Plast Surg 2017;79(02):166-173

4 Wolfe SW, Hotchkiss RN, Prderson WC, Kozin SH. Green's Operative Hand Surgery. 6th ed. Philadelphia, PA: Elsevier Churchill Livingstone; 2011

5 Sturman MJ, Duran RJ. Late results of finger-tip injuries. J Bone Joint Surg 1963;45A:289-298

6 Bojsen-Moller J, Pers M, Schmidt A. Finger-tip injuries: late results. Acta Chir Scand 1961;122:177-183

7 Lee DC, Kim JS, Ki SH, Roh SY, Yang JW, Chung KC. Partial second toe pulp free flap for fingertip reconstruction. Plast Reconstr Surg 2008;121(03):899-907

8 Giladi AM, Aliu O, Chung KC. The effect of medicaid expansion on delivery of finger and thumb replantation care to medicaid beneficiaries and the uninsured. Plast Reconstr Surg 2015;136(05):640e-647e

9 Sears ED, Shin R, Prosser LA, Chung KC. Economic analysis of revision amputation and replantation treatment of finger amputation injuries. Plast Reconstr Surg 2014;133(04):827-840

10 Google Forms. Available at: https://docs.google.com/forms/d/e/ 1FAIpQLSdTwbIb8AYcXVFgrcvIJS4FKlpkwWHs0lmfvb9dalHIGZAMKg/viewform?vc=0\&c=0\&w=1. Accessed December 26, 2019

11 ResearchGate. https://www.researchgate.net/profile/Tommy_Nai_ Jen_Chang. Accessed December 26, 2019

12 Linkedin. https://www.linkedin.com/in/tommy-nai-jen-chang54599437/?trk=nav_responsive_tab_profile_pic. Accessed December 26, 2019

13 Facebook. https://www.facebook.com/tommynjchang. Accessed December 26, 2019

14 International Microsurgery Club. Available at: https://www.facebook. com/groups/1702063276733451/. Accessed December 26, 2019

15 Chang TNJ. Knowledge revolution through online interactive platform: international microsurgery club. International Microsurgery Journal. 2017;1(02):1
16 Lin JAJ, Omar UF, Mateev M, Chang TNJ. From virtuality to reality: Social media facilitates the interaction between global microsurgeons. Int Microsurg J. 2017;1:2

17 Chang TN, Hsieh F, Wang ZT, Kwon SH, Lin JA, Tang ET. Social media mediate the education of the global microsurgeons: the experience from International Microsurgery Club. Microsurgery 2018;38(05):596-597

18 Kwon SH, Goh R, Wang ZT, et al. Tips for making a successful online microsurgery educational platform: the experience of international microsurgery club. Plast Reconstr Surg 2019;143(01):221e-233e

19 Takeda A, Fukuda R, Takahashi T, Nakamura T, Ui K, Uchinuma E. Fingertip reconstruction by nail bed grafting using thenar flap. Aesthetic Plast Surg 2002;26(02):142-145

20 Lin JA, Hsu AT, Huang JJ, et al. Impact of social media on current medical conferences. J Reconstr Microsurg 2019;35(06):452-461

21 Kwon SH, Lee CH, Hsu AT, et al. Use of social media and an online survey to discuss complex reconstructive surgery: a case of upper lip reconstruction with 402 responses from international microsurgeons. J Reconstr Microsurg 2018;34(06):413-419

22 Zhang X, Wen S, Wang B, Wang Q, Li C, Zhu H. Reconstruction of circulation in the fingertip without vein repair in zone I replantation. J Hand Surg Am 2008;33(09):1597-1601

23 Yabe T, Muraoka M, Motomura H, Ozawa T. Fingertip replantation using a single volar arteriovenous anastomosis and drainage with a transverse tip incision. J Hand Surg Am 2001;26(06):1120-1124

24 Breahna A, Siddiqui A, Fitzgerald O'Connor E, Iwuagwu FC. Replantation of digits: a review of predictive factors for survival. J Hand Surg Eur Vol 2016;41(07):753-757

25 Akyürek M, Safak T, Keçik A. Fingertip replantation at or distal to the nail base: use of the technique of artery-only anastomosis. Ann Plast Surg 2001;46(06):605-612

26 Lin TS, Jeng SF, Chiang YC. Fingertip replantation using the subdermal pocket procedure. Plast Reconstr Surg 2004;113 (01):247-253

27 Cobbett JR. Free digital transfer. Report of a case of transfer of a great toe to replace an amputated thumb. J Bone Joint Surg $\mathrm{Br}$ 1969;51(04): 677-679

28 Sebastin SJ, Chung KC. A systematic review of the outcomes of replantation of distal digital amputation. Plast Reconstr Surg 2011;128(03):723-737

29 Tamai S. History of microsurgery. Plast Reconstr Surg 2009;124(6, Suppl)e282-e294

30 Kim WK, Lim JH, Han SK. Fingertip replantations: clinical evaluation of 135 digits. Plast Reconstr Surg 1996;98(03):470-476

31 Mihara M, Nakanishi M, Nakashima M, Narushima M, Gonda K, Koshima I. Distal phalanx replantation using the delayed venous method: a high success rate in 21 cases without specialised technique. J Plast Reconstr Aesthet Surg 2008;61(01):88-93

32 Gordon L, Leitner DW, Buncke HJ, Alpert BS. Partial nail plate removal after digital replantation as an alternative method of venous drainage. J Hand Surg Am 1985;10(03):360-364

33 Batchelor AG, Davison P, Sully L. The salvage of congested skin flaps by the application of leeches. Br J Plast Surg 1984;37(03):358-360

34 Chen YC, Chan FC, Hsu CC, Lin YT, Chen CT, Lin CH. Fingertip replantation without venous anastomosis. Ann Plast Surg 2013; $70(03): 284-288$

35 Qiu SS, Hsu CC, Hanna SA, et al. Negative pressure wound therapy for the management of flaps with venous congestion. Microsurgery 2016;36(06):467-473

36 Dadaci M, Ince B, Altuntas Z, Bitik O, Uzun H, Bilgen F. A novel technique for distal fingertip replantation: Polypropylene suture guided interpositional vein graft. J Plast Surg Hand Surg 2015;49(05):280-283

37 Abdelrahman M. The microsurgery fellowship at chang gung memorial hospital: blossom of caterpillars. Plast Reconstr Surg Glob Open 2015;3(04):e376

38 Chen CT, Wei FC, Chen HC, Chuang CC, Chen HT, Hsu WM. Distal phalanx replantation. Microsurgery 1994;15(01):77-82 